\title{
The Static Analysis of The Impact of Damaged Frame column on The Overall Structure Based on ABAQUS
}

\author{
Zhenfu Chen ${ }^{1,}$, Sihang Lai ${ }^{2, b}$ \\ ${ }^{1}$ key laboratory of Treatment of Disasters in Engineering \\ University of South China, hengyang 421000, China; \\ ${ }^{2}$ School of civil engineering University of South China, hengyang 421000, China. \\ aczf37@163.com, ${ }^{\mathrm{b}} 340377771 @ q q . c o m$,
}

\begin{abstract}
Keywords: RC frame structure of high rise;damage of local members;reinforcement of members;static nonlinear analysis.
\end{abstract}

\begin{abstract}
This article mainly talks about the RC frame structure of high rise . Frame structure of RC beam element is studied based on the finite element software ABAQUS, and uniaxial constitutive relation of containing material failure principle of reinforcement and concrete is constructed ,and then the influence of the overall frame structure after damage of local members in three different working conditions (the middle,corner and side column of bottom structure ) respectively in serviceability limit state is studied .Internal force analysis of the whole structure is accomplished by using the static nonlinear analysis method, as well as the comparative analysis with the original complete structure.Results show that adjacent transbeams get more damage than longerons after damage of columns of bottom structure , and the adjacent beam should be strengthened , and the adjacent beams of the bottom and top are very important.
\end{abstract}

\section{Introduction}

Our country takes much account of repairing the damage to the building structure work particularly seriously in recent years, including the wreck of a lot of structures,or structural damage caused by many factors.

During the life of the structure, the actual loading of main structure is far more than the designed loading.The main structure being crushed, insufficient design strength grade or cutting corners during construction can cause insufficient intensity of local beam and other members . Masonry buildings once undergoing earthquakes with small damage still can maintain normal use after identification and reinforcement.Identification and reinforcement should be accomplished during a local modification of masonry structure, especially when bearing members is modified.

\section{Object of study}

This study takes RC frame structure of 11 floors, 2 spans and 11 arches as object.Finite element models of RC frame have been set up and numerical simulation been made by using ABAQUS.In numerical simulation,frame construction was modeled based on beam element. The bottom columns are in height of $2000 \mathrm{~mm}$, and two to the top floor height is $2800 \mathrm{~mm}$.members size : the frame column is $600 \mathrm{~mm} \times 600 \mathrm{~mm}$, longitudinal frame beam is $250 \mathrm{~mm} * 500 \mathrm{~mm}$, lateral frame beam is $250 \mathrm{~mm} \times 300 \mathrm{~mm}$.Grade of steel is HPB300 and HRB335,strength grade of concrete is C30. Boards and walls are not set because of the beam column model, and the quality of the walls and boards is converted to beam structure in case of horizontal force caused by the lack of boards and walls. The number of model unit is 17490,the degree of freedom is 49236. 


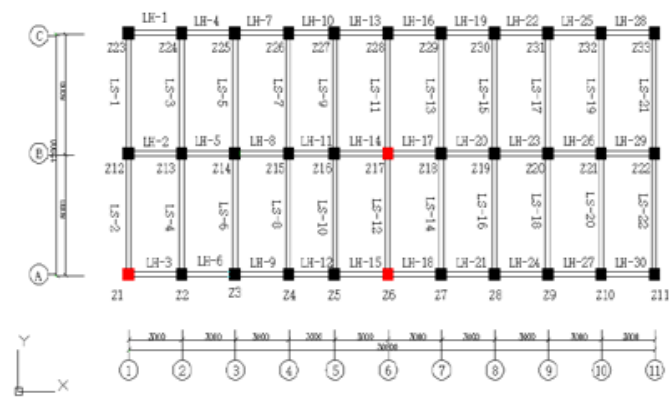

Fig 1.structural plan of standard layer

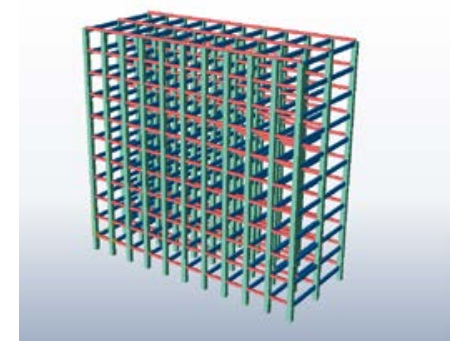

Fig 2.Model drawing of beam element structure

Figure 1 show the structural plan of standard layer of RC frame structure.In this paper,compressive deformation of the bottom column Z17 in serviceability limit state was simulated.Figure 2 shows the structural modeling based on example of beam element stimulation engineering.

\section{Constitutive relation of materials}

So far,the experimental study and numerical simulation analysis is an effective approach to study concrete structure mechanics performance.The constitutive relationship of concrete and the structural nonlinear analysis are two important topics in the study of concrete structure mechanics performance.With the development of computer technology and numerical simulation theory, the finite element method has become a kind of important means to study concrete structure. Mechanical properties of concrete material must be considered in the numerical analysis of concrete structure.

The fourth strength theory is used to determine the plastic in classical plasticity model of the ABAQUS , but it can't reflect the difference of tension and compression strength of concrete.And its own concrete plastic damage model considers tension and compression and plastic damage at meantime,however, it cannot be used in beam unit.Therefore,this numerical simulation is based on UConcrete02 in subroutine of umat and material model of USteel02.The following table lists C10,C30 concrete of canonical recommendation and reinforced material data of HPB300,HRB335. Beam element of Beam21 is used in concrete,and steels command rebar order into concrete. Because the pretreatment module cae of the current ABAQUS version dose not support rebar orders, ABAQUS keywords are needed for processing.

Table 1.constitutive parameter of pain concrete of canonical recommendation

\begin{tabular}{|c|c|c|c|c|c|c|c|c|c|c|}
\hline & $\mathbf{E}_{\mathrm{c}}$ & $v_{0}$ & $f_{\infty 0}$ & $\varepsilon_{0}$ & $f_{a}$ & $\varepsilon_{1}$ & $d_{c x}$ & $f_{t}$ & $\mathbf{s}$ & $\boldsymbol{E}$ \\
\hline $\mathrm{C} 10$ & $1.75 \times 10^{\mathbf{1 0}}$ & 0.18 & 1. $21 \times 10^{7}$ & 1. $383 \times 10^{5}$ & $1.03 \times 10^{7}$ & 0.0038 & 0.5 & $1.779 \times 10^{6}$ & $1.8 \times 10^{\circ}$ & 0.002 \\
\hline C30 & $3 \times 10^{10}$ & 0.2 & $2.8 \times 10^{7}$ & $1.879 \times 10^{5}$ & $2.38 \times 10^{7}$ & 0.0038 & 0.5 & $2.8 \times 10^{6}$ & $2.98 \times 10^{5}$ & 0.002 \\
\hline
\end{tabular}

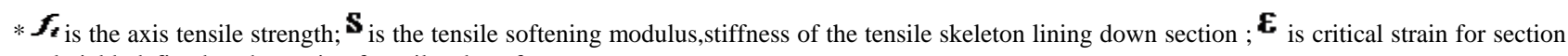
steel yield, defined as the strain of tensile edge of concrete. 
Table 2. constitutive parameter of reinforcement

\begin{tabular}{|l|l|l|l|l|l|}
\hline & \multicolumn{1}{|c|}{$\mathbf{E}_{\mathbf{0}}$} & \multicolumn{1}{c|}{$f_{\mathrm{pl}}$} & $\mathrm{d}_{1}$ & $\frac{f}{f_{\mathbf{y} 1} / E_{\mathbf{0}}}$ & $\bar{f}$ \\
\hline HPB300 & $2.1 \times 10^{11}$ & $3.52 \times 10^{\mathbf{2}}$ & 0.01 & 36.0 & $4.93 \times 10^{\mathbf{2}}$ \\
\hline HRB335 & $2 \times 10^{11}$ & $4.56 \times 10^{\mathbf{2}}$ & 0.01 & 36.0 & $5.18 \times 10^{\mathbf{2}}$ \\
\hline
\end{tabular}

${ }_{*} f_{\mathrm{pl}}$ is the initial yield strength; $\mathrm{d}_{1}$ is yield stiffness coefficient, equal to the ratio of the yield the stiffness and the elastic modulus; ${ }^{\frac{f}{f_{p_{1}} \kappa_{0}}}$ is the ultimate plastic deformation rate; $\bar{f}$ is average for the ultimate strength.

The advantage of this material model is to study the transverse stirrups on the constraint of concrete by changing the peak stress,peak strain and slope of softening period of compression skeleton curve of concrete, and the influence of the residual strength of concrete can be considered .When rise and fall of concrete in tension are straight lines, the initial cracking of concrete can be considered.

Concrete fiber uses the revised model of Kent - Park ${ }^{[\mathbf{I}]}$, the reaction force - displacement relationship is shown in figure 3.

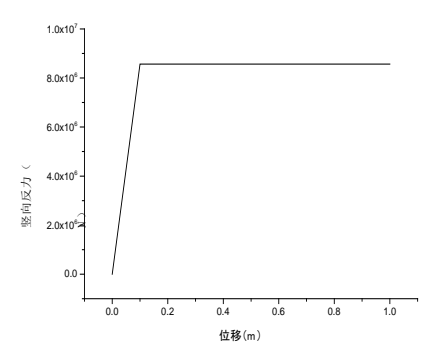

uniaxial loading curve of plain concrete

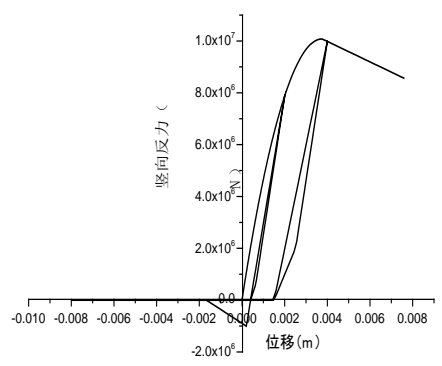

reciprocating loading curve of concrete

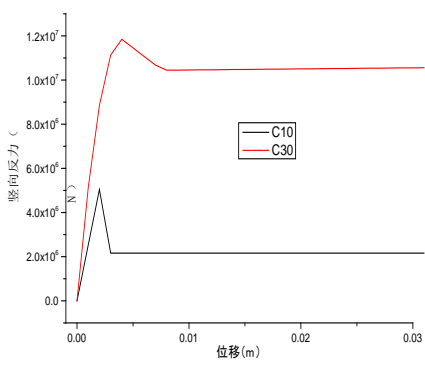

Fig 3.constitutive parameter of concrete

Fig 4.reaction-displacement curve of sample summit

Figure 4 shows the model that takes bottom column of $2 \mathrm{~m} \times 0.6 \mathrm{~m} \times 0.6 \mathrm{~m}$ as a example,it's a relationship diagram of summit action and displacement of axial displacement based on RC column C10 and C30. In the figure,when vertical drift of RC column C30 is at $5.44 \mathrm{~mm}$,concrete and reinforcement are under pressure together at ascending stage,reaching maximum summit reaction,and concrete reaches threshold of pressive strength.Falling stage appears when displacement is at $5.4-8.3 \mathrm{~mm}$. When drift is at $8.3 \mathrm{~mm}$,concrete falls apart,and members enter into complete yield stage.RC column $\mathrm{C} 10$ is the damaged members that has yield failure in serviceability limit state during simulation of local damage caused by operation failure and other factors. When C30 reaches reaction threshold, column C10 has already entered into plastic yield stage,and its yield displacement is determined according to formula suggested by Priestley ${ }^{\mathbf{2} \mathbf{1}}$.Limit displacement is defined as numerical value of summit displacement when bearing capacity decreases to $85 \%$ of the maximum ${ }^{[3]}$.

\section{Static Elastoplastic Analysis}

Structural static elastoplastic analysis method got earlier research and application in foreign countries.Static elastoplastic analysis method is also known as push-over method, which is based on the FEMA-273 seismic evaluation methods and ATC-40 report, is a kind of method between elastic analysis and dynamic elastoplastic analysis , whose theoretical core is "target displacement method" and "bearing capacity spectrum method" .

In this paper,elastoplastic analysis of RC frame structure was made by using ABAQUS software,according to the principle of static elastoplastic analysis method and the specific calculation steps, and the application of static elastoplastic analysis in practice is further clarified through the analysis of an engineering example.

\subsection{Stress analysis in serviceability limit state}

In order to simulate damage working condition of the bottom column more veritably,the scheme of weakening the material strength and stiffness of the damaged bottom column is adopted to 
simulate vertical displacement of compressive deformation caused by damages due to careless construction or stiffness of RC column not meeting the design requirements.

In serviceability limit state, material properties of concrete of bottom middle column Z17 is debugged to strength of concrete C10,causing displacement of vertical compression deformation in serviceability limit state.

\subsubsection{The final structure displacement of static elastoplastic analysis results} Story maximum node displacement is shown in figure 5 .
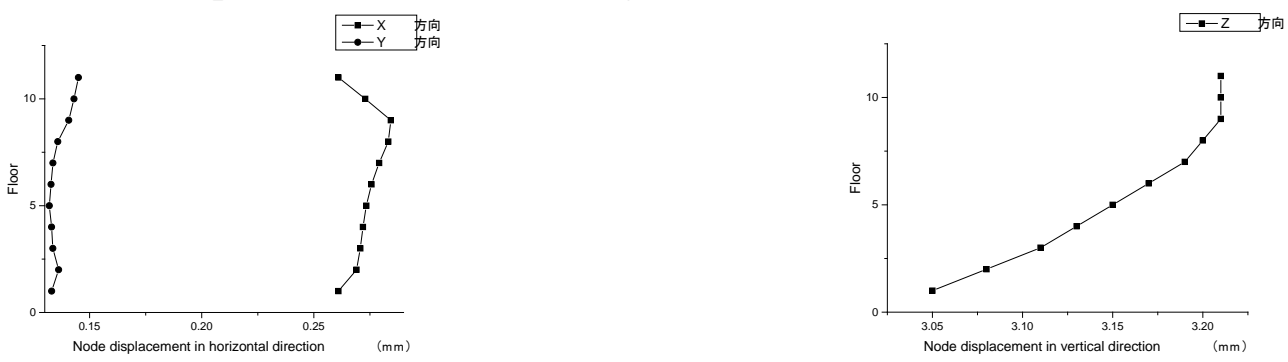

Fig 5.Floor maximum node displacement curve

\section{Results analysis of the maximum story node displacement}

1)when bearing capacity is in serviceability limit state,the ratio of story relative drift and layers height is less than 1/50 according to elastoplastic calculation,meeting the specification requirements.

2)Story maximum node displacement of model Y-direction is less than X-direction's. The maximum node displacement in X-direction is the maximum node displacement on third floor in model of damaged middle column ,which is $0.28435 \mathrm{~mm}$; The maximum node displacement in Y-direction is the maximum node displacement of middle-bottom layer,which is $0.145 \mathrm{~mm}$; The maximum node displacement in vertical direction is the maximum node displacement of floor 9-10,which is $3.21 \mathrm{~mm}$.

3)It can be seen that the maximum node displacement in X-direction has a little change with the increase if layer,but the maximum node displacement in Y-direction is increasing as layer increases,displacement decrease at floor 9-10, and at a large scale; the maximum node displacement in vertical direction is increasing as layer increases,reaching peak value of $3.21 \mathrm{~mm}$, and node displacement has no obvious change.

\subsubsection{Structural internal force analysis in serviceability limit state}

1.Figure of maximum internal force between the stories is shown in figure 6 .

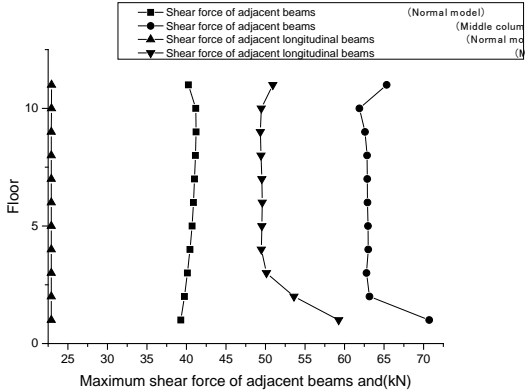

错误!

Maximum shearing force of adjacent beam ends
错误!

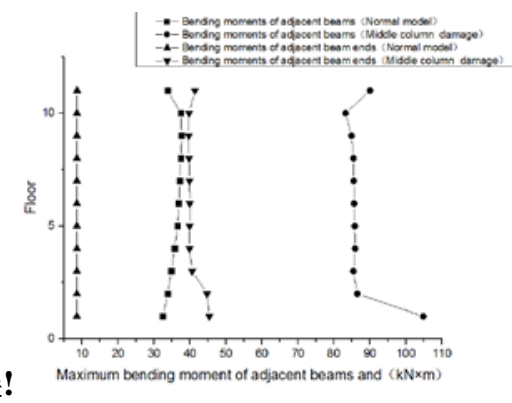

Maximum moment curve of adjacent beam end

Fig. 6 story maximum inter force curve

\section{Results analysis of inter force}

1)we can tell from the curve of story maximum internal force that shear force and bending moment of adjacent beam-end on story 1-2 and story 10-11 in the model of damaged middle column in bottom both changed a lot,decreasing on story 1-3. Shear force and bending moment increased a lot at top of model.

2) The model of damaged middle column in bottom makes the biggest change on beam-end shear force and bending moment of adjacent beams in serviceability limit state,and maximum shear is $70.71 \mathrm{kN}$, maximum bending moment is $104.84 \mathrm{kN} \times \mathrm{m}$, twice as large as the one of longeron.We can see that the damage of bottom columns has the biggest influence on adjacent transbeam,and the 
adjacent beam members should be strengthened.

\subsubsection{Analysis of plastic inter force of adjacent beam}

When bearing capacity is in the serviceability limit state,the bottom damaged middle column model has a wide range of impact on the overall structure.As following is the statistical analysis of range of damage degree of surrounding beams from the model of damaged middle column in working condition .(In the figure,the part of plastic index $\geqq 1$ is where the plastic yielding failure happens )

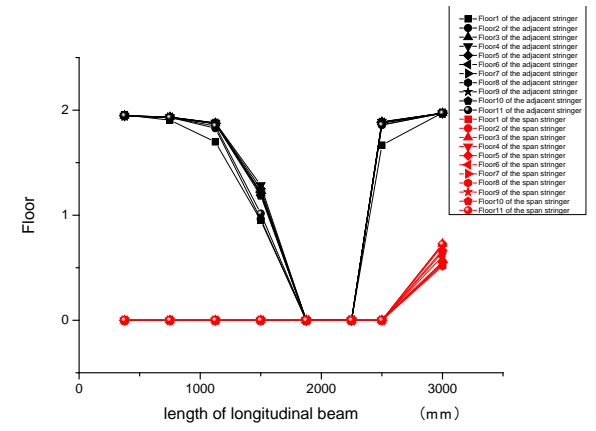

Fig.7 Plastic deformation index of longitudinal beam distribution

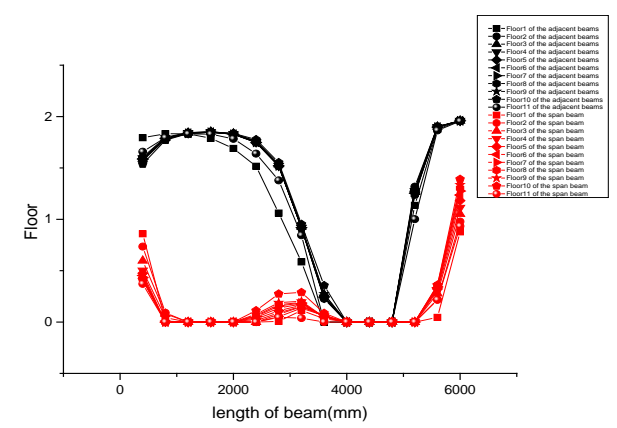

Fig.8 Plastic deformation index of lateral beam distribution

From the plasticity exponential distributions of adjacent stringers and september stringers in Fig. 7 and Fig. 8, it can be concluded that the plastic beams near the longitudinal beams and the adjacent beams have been subjected to plastic yielding failure. And the damage area is larger at the beam end farther away from the center column. The plasticity index of the span girder is not affected by plastic deformation. And the span beam is plastic yield failure at the beam end farther away from the center column, but the damage area is smaller and the relative influence is smaller. From the different floors of the beam can be seen in different floors of the beam, the higher the floor near the beam end of the plastic damage occurred in the larger, while the farther away from the beam end of the beam is the opposite, but the difference by the floor is not obvious.

\section{Conclusion}

(1)The simulation of sill column 's damage occurring in practical working condition will be more realistic by lowering the vertical displacement of bottom column 's material during the process of bearing capacity to simulate the compressive deformation caused by damage and failure because of construction,collision,human or natural factors.Among the static elastoplastic analysis results on models in serviceability limit state,the maximum node placement in $\mathrm{X}$ direction is much bigger than $\mathrm{X}$ direction's,and the maximum node displacement is increasing as layer increases until story 8,decreasing on floor 9-11; the maximum node placement in vertical direction is increasing as layer increases.

(2)Damage of bottom middle column has big influence on the surrounding members,adjacent transbeams and longerons all have concrete yield failure, but compared with longerons, the area of yield failure of transbeams is larger and plastic failure is more serious,the influence on surrounding beams and beam ends of damaged middle column is greater than in-span's,and influence on next-span beam column is smaller, especially on columns, with little yield.As for layers, bottom column 's damage and failure has a greater impact on adjacent beam column of damaged column on floor 1-3 and the shear force and bending moment of damaged top beam on bottom middle column will increase ,therefore,during practical working condition,the adjacent beams should be strengthened after bottom column damaged,and adjacent beams of bottom and top are particularly important.

(3)In serviceability limit state,middle column's wreck and damage of model will cause serious damage to adjacent members,so when yield failure occurs to bottom column of high rise RC frame structure because of various factors, it needs repairing immediately to ensure that compressive deformation of damaged columns in model won't continue, it is very necessary to strengthen the important members of overall structure and lower yield range and damage degree of adjacent beams. 


\section{Acknowledgments}

This work was supported by the National Natural Science Foundation of China (Grant No. 51678286, 51479098) and the Natural Science Foundation of Hunan Province (Grant No. 2016JJ2107) and the Initiative Scientific Research Program of Education Department of Hunan (Grant No. 13A082) and the Initiative Scientific Research Program of University of south china. YuanChu Gan QiuWan Tao

*gan_yuanchu@126.com; taoqiuwan@163.com;

(* Corresponding author e-mail )

\section{References}

[1]Kent D C, Park R. Flexural members with confinedconcrete[J]. Journal of the Structural Division, 1971.

[2] Priestley M J N. Brief comments on elastic flexibility of RC frames and significance to seismicdesign[J]. National Society for Earthquake Engineering, 1998..

[3] GAO Fei, LIU Wenfeng, FU Xingpan. Statistical analysis of displacement angles of RC columns in china[J]. .Journal of Qing Dao University of Science and Technology , 2009.

[4] Zhang Wangxi,Xu Shuai,Li Qingling.Influence of Local members strengthening on Overall Performance of RC Frame Structure[J].Journal of disaster prevention and mitigation of engineering, April,2003

[5]Zhou Jin.Static elastoplastic analysis of steel frame based on SAP2000[J]. Architecture of Jiangxi.Agust,2013.

[6]Nie Jianguo,Wang Yuhang. Comparison study of constitutive model of concrete in ABAQUS for static analysis of structures. [J]. engineering mechanics,April,2013.

[7] Gao Xiangling,Zhang Yeshu,Li Jie.Numerical simulation of failure process of RC columns based on fiber beam element in ABAQUS[J].Structural Engineers,December,2013.

[8] Cheng Michun,Liu Huawei. Application of RC Material Constitutive Model Based on the Secondary Development of ABAQUS Fiber Beam Element.September,2015. 